\title{
GENDER DIFFERENCES IN ORAL CARE HABITS, ATTITUDES AND BEHAVIOURS OF ADOLESCENTS IN THE CITY OF KLAIPEDA

\author{
Šarūnẻ Barsevičiené ${ }^{1}$, Eglè Žymantiené $\dot{~}^{2}$, Jurgita Andruškiené $\dot{~}^{3}$
}

\begin{abstract}
:
Background. For many, the adolescent years can be a difficult emotional period and a time when dental and medical needs may be neglected. Oral health is one of the most unmet health care needs of adolescents. Oral diseases can have a profound effect on overall health, including pain, missed school, heart disease, and even death (Silk and Kwok, 2017).

Aim of the survey: to study the gender differences in oral hygiene habits, attitudes and behaviours in Klaipeda city adolescents sample.

Methods: There were 1206 questionnaires distributed (response rate $95.3 \%$ ). A total of 1150 adolescents participated in the study, with $52.4 \%$ being girls, and the mean age was 13.4 years.

Results. The study results demonstrated girls more often brushed their teeth than boys, $86.8 \%$ and $68.5 \%$, respectively $(\mathrm{p}<0.001)$. Almost all the participants $(98.5 \%)$ used toothpaste and a toothbrush on a daily basis, but girls more often used dental floss $(66.3 \%$ as compared to boys $33.7 \%$, p <0.001), mouthwash $(60.3 \%$ as compared to boys $39.7 \%$, p <0.001) and other dental care products $(79.5 \%$ as compared to boys $20.5 \%, \mathrm{p}<0.05)$ for toothbrushing and daily dental care. The girls brushed their teeth in the morning $(92.9 \%)$ and before bedtime $(91.0 \%)$, as well as the boys $(85.0 \%$ and $77.5 \%$, respectively, $\mathrm{p}<0.001$ )

Conclusions. Girls demonstrated better oral health care habits, comparing to boys. Boys had greater, as compared to girls, dental fear, restricting them from having regular appointments for check-ups at the dental office. Girls more frequently than boys had an attitude that teeth should be kept clean for aesthetic purposes and in order to ensure their longevity. Girls preferred to seek a dentist's help as soon as it is needed and to maintain good oral health, because it's essential to human health in general.
\end{abstract}

UDC Classification: 613.9; DOI: http://dx.doi.org/10.12955/cbup.v6.1263

Keywords: Oral Care Habits, Attitudes, Behaviours, Adolescents

\section{Introduction}

Adolescence is a transitional stage during which a child develops into an adult incurring dramatic physical, emotional, as well as oral health behavior changes. The 2016 Health Behaviour in Schoolaged Children (HBSC) study covering 41 countries has revealed that a prevalence of positive life satisfaction significantly declined during the period from 11 to 15 years, with boys reporting a significantly higher prevalence of positive life satisfaction than girls (Inchley, 2016).

The results of a integrative review revealed that dental treatment avoidance (cancelled/missed dental appointments) and non-attendance were more characteristic for boys as compared to girls (Fagerstad et al., 2016). It could be due to poorer oral health status among boys than girls, as a well known factor behind dental avoidance (Kanli et al., 2008). Dental treatment avoidance and non-attendance also was higher among older age adolescents, as compared to younger ones. This can be explained by the fact that older adolescents likely more often made their own decisions influenced by their own priorities (Skaret et al., 2000).

Dental avoidance and non-attendance can be partly explained by dental anxiety and fear of dentists, the prevalence of it ranged between 3.3 and 19.0\% (Poulton et al., 2001; Stenebrand et al., 2013) in adolescents. Dental anxiety showed decreasing prevalence in Swedish 15 year olds during a 30 year period from 1973 to 2003, due to improved communication skills of dental staff, pain reduction, recall intervals and improved oral health and individual dental hygiene, exclusively in Sweden.

Regular tooth brushing in the adolescent age in Norway more than once a day predicted more stable tooth brushing habits later in life (Astrom, 2004). Prevalence of recommended toothbrushing behavior (more than once a day), has increased among the 11-15 years adolescents in 20 countries (regions) participating in the HBSC research, during the time period 1994-2010 (Honkala et al., 2015), except in Scandinavia, which had already attained a very high level in 1994. The highest increase (more than +

\footnotetext{
${ }^{1}$ Oral Care and Nutrition Department, Klaipeda State University of Applied Sciences, Lithuania, s.barseviciene@kvk.lt

${ }^{2}$ Oral Care and Nutrition Department, Klaipeda State University of Applied Sciences, Lithuania, e.zymantiene@kvk.lt

${ }^{3}$ Oral Care and Nutrition Department, Klaipeda State University of Applied Sciences, Lithuania, j.andruskiene@kvk.lt
} 
16\%) was observed in Estonia, Russia, Latvia, Finland and in Flemish Belgium. Girls had higher prevalence of toothbrushing than boys $(\mathrm{OR}=2.06,99 \%$ CI 2.03-2.10). However, the increasing trend was stronger among boys (OR (2010 vs 1994) for boys 1.60; for girls 1.48), and among the younger adolescents (OR (2010 vs 1994) for 11-year-olds 1.64; for 15-year-olds 1.45).

The results of a cross-sectional study, which was based on an earlier clinical, two-year toothpaste intervention study, have demonstrated that the majority (93\%) of adolescents in Sweden brushed their teeth every day, while 7\% were doing it occasionally. Most of the survey respondents (77\%) brushed teeth twice a day, while $12 \%$ brushed just once a day. About half of those brushing just once a day forgot to brush in the evening. Similarly, more than half of the adolescents $(53 \%)$ used $1 \mathrm{~cm}$ of toothpaste or less on their toothbrush. Moreover, $49 \%$ brushed for less than $2 \mathrm{~min}, 41 \%$ brushed for $2 \mathrm{~min}$ and $10 \%$ for more than $2 \mathrm{~min}$. The majority (73\%) rinsed with water after toothbrushing. A difference between boys and girls was also observed; $87 \%$ of the girls brushed twice a day, whereas only $67 \%$ of the boys did so and boys more frequently forgot in the evening (Nordstrom and Birkhed, 2017).

Toothbrushing frequency was significantly lower in Lithuania (61\% 15 years old girls and $42 \%$ of the boys brushed their teeth more than once a day), as compared to Sweden (88\% and 74\%, respectively), France (88\% and 73\%, respectively) or Denmark (83\% and 75\%, respectively) (HBSC 2013/2014 Survey). The unfavourable and specific situation in Lithuania, described as illiteracy and ignorance in dental hygiene matters (among adolescents and adults), requires the investigation of oral health habits, attitudes and behaviours among the adolescents in the most wide and explicit way.

Aim: to study the gender differences in oral hygiene habits, attitudes and behaviours in Klaipeda city adolescents sample.

\section{Data and Methods}

Procedure

There were 1206 questionnaires distributed (response rate $95.3 \%)$ at randomly selected schools $(\mathrm{N}=5$, $17.85 \%$ of all schools in Klaipeda city) in November, 2017. Questionnaires were applied in the classrooms, during school time, with all participating adolescents present, under supervision of school public health specialists. For participants under 16 years old, a written informed consent was obtained from their parents. Consent forms were also obtained from every school director. The study was approved by the Bioethics Committee of Klaipeda State University of Applied Sciences. Questionnaires were analyzed at the Faculty of Health Sciences, Klaipeda State University of Applied Sciences. The collected information was anonymous, for personal data only gender and age were recorded.

Participants

In total 1150 adolescents participated in the study, $52.4 \%$ were girls with a mean age of 13.4 years.

The Questionnaire

The questionnaire consisted of 28 statements organized in five dimensions: dental fear (nine statements), esthetic and dental hygiene (six statements), concern with health (four statements), dental problems prevention (six statements) and general health (three statements). The mean was calculated for each statement which was assessed by the respondents in a Likert type scale (Totally agree - 1; Totally disagree - 5). Higher mean scores in questions 1-6, 13-16, 18-21 and 25 were interpreted as showing a better attitude towards oral health. Higher mean scores in questions 7-12, 17, 22-24, 26-28 meant worse attitude towards oral health. The questionnaire contained three additional multiple-choise questions on tooth brushing frequency, instruments used for dental hygiene and time of toothbrushing. The questionnaire was forward and back translated from/to Lithuanian/English languages prior to the survey. The authors of the English version of the questionnaire have approved the results of the lingual adaptation process. The validity of the questionnaire was tested, the Cronbach's alpha coefficient ranged from 0.518 (General and oral health) to 0.857 (Dental aesthetics) in the dimensions.

Statistical Analysis

The data was analysed using IBM SPSS.20 software. A Pearson's Chi - squered test was used to compare the distribution of variables and a Student's $\mathrm{t}$ - test was used for the statistical examination of two population means. 


\section{Results}

Girls more often than boys brushed their teeth at least once a day, $86.8 \%$ (95\% CI 83.91-89.33) vs $68.5 \%(95 \%$ CI $64.60-72.39), \mathrm{p}<0.001 \quad\left(\chi^{2}=57.887, \mathrm{df}=3\right)$. Girls more often used additional oral healthcare products (mouth rinse, tongue scraper and interproximal tooth brush) along with traditionally used manual tooth brush and tooth paste, $61.0 \%$ (95\% CI 57.10-64.89) vs $44.4 \%$ (95\% CI 40.28-48.61), $\mathrm{p}<0.001\left(\chi^{2}=31.754, \mathrm{df}=1\right)$.

Table 1 shows the mean differences between boys and girls in dental fear, dental aesthetics, health concerns, oral problems prevention and general health assessment dimensions.

Dental fear dimension analysis (Table 1) showed that girls had significantly higher means (reflecting lesser dental fear) as compared to boys, in the statements expressing the conscious willingness to visit the dentist even without their parents' involvement ( 3.47 in female vs 3.30 in male, $p<0.05$ ) and even in cases when a tooth did not hurt (3.66 vs 3.42, p<0.05). Girls were less frightened (3.26 in girls vs 3.52 in boys, $\mathrm{p}<0.05$ ) and nervous (3.35 vs $3.58, \mathrm{p}<0.05)$, as compared with boys, while visiting a dentist, even during annual check-ups.

Dental aesthetic dimension analysis (Table 1) revealed significant gender differences, proving that girls more often than boys, were keeping their teeth clean because of dental aesthetic issues (4.79 in girls vs 4.52 in boys, $\mathrm{p}<0.001)$ and for attractive appearances (4.73 vs $4.47, \mathrm{p}<0.001)$.

Analysis of health concerns dimension (Table 1) showed that girls more often than boys, would seek the services of a dentist immediately in the case of any dental problem (girls 1.85 vs boys 2.12, $\mathrm{p}<0.001)$.

Oral health problems prevention dimension analysis showed (Table 1) higher mean scores in boys as compared to girls demonstrating poorer attitude towards regular visits to the dentist at least once a year ( 1.81 vs $1.65, \mathrm{p}<0.05)$. Boys were not so sure, as compared to girls, that oral health education should start from early childhood (1.91 vs $1.73, \mathrm{p}<0.05)$.

General health dimension analysis demonstrated (Table 1) that girls had better understanding, as compared to boys, that teeth were important for health of the whole body $(1.81$ vs $1.62, p<0.05)$ as well as the attitude that having good oral health was important to feel good in general (2.01 vs 1.88 , $\mathrm{p}<0.05)$.

\section{Discussion}

The results of our study demonstrated significant differences in tooth brushing habits between girls and boys. The findings of our study were in line with the results of the previous studies, conducted in the 39 WHO European countries (HBSC International Report, 2013/2014), showing greater female than male commitment towards regular tooth brushing in all age groups and all countries. Tooth brushing frequency (more than once a day) among the adolescents in Klaipeda city was similar to Scotland (86.0\% in girls vs $71.0 \%$ in boys 13 years old adolescents), Norway ( $80.0 \%$ vs $69.0 \%$, respectively) or Wales $(83.0 \%$ vs $65.0 \%$, respectively). The most interesting findings were the noticeable differences of tooth brushing frequency in the representative for the adolescents sample of Lithuanian 13 year olds (59\% girls and 39\% boys brushed their teeth more than once a day) and Klaipeda city adolescents $(86.8 \%$ and $68.5 \%$, respectively). The crucial difference could be explained by the fact that Klaipeda more than other cities was involved in health promoting activities, initiated by Klaipeda City Public Health Bureau specialists, working in schools. On the other hand, the frequency of tooth brushing could increase due to the increasing role of dental hygienists in oral health promotion in the community during the last decade. The differences also could be influenced by the research limitations, such as a lack of representativeness of the research sample of the Klaipeda city adolescent population.

The authors of this study used the same questionnaire which was used to survey the adolescents of Portugal (Soares Luis et al., 2014) and there were similarities in the results. This study showed that boys had a greater, as compared to girls, dental fear, restricting them from having regular appointments for check-ups at the dental office. Boys more often than girls considered visits for dental check-ups as stressful and increasing anxiety. The survey of Portuguese adolescents showed very similar results. There they found that boys in Portugal did not seek dental care independently, presenting a statistically significant increased fear of dental treatment than girls $(\mathrm{p}<0.05)$. The same 
Table 1: Mean differences between genders (Lower mean scores mean better attitude towards oral health in $\mathbf{R}$ marked questions).

\begin{tabular}{|c|c|c|c|}
\hline \multirow[b]{2}{*}{ Questions } & \multicolumn{2}{|c|}{ Gender } & \multirow[b]{2}{*}{$\mathbf{p}$} \\
\hline & $\begin{array}{l}\text { Girls }(\mathrm{N}=603) \\
\text { Mean (st.dev.) }\end{array}$ & $\begin{array}{l}\text { Boys (N=547) } \\
\text { Mean (st.dev.) }\end{array}$ & \\
\hline \multicolumn{4}{|l|}{$\begin{array}{ll} & \text { Dental Fear dimension } \\
\end{array}$} \\
\hline $\begin{array}{l}\text { 13. If my parents did not take me regularly to the dentist, I would not } \\
\text { go to the appointment }\end{array}$ & $3.47(1.159)$ & $3.30(1.194)$ & 0.014 \\
\hline $\begin{array}{l}\text { 14. I do not like going to the dentist, I only go there when a tooth hurts } \\
\text { a lot }\end{array}$ & $3.66(1.118)$ & $3.42(1.206)$ & 0.001 \\
\hline 15. Going to the dentist is an experience that frights me lot & $3.26(1.336)$ & $3.52(1.283)$ & 0.001 \\
\hline $\begin{array}{l}\text { 16. I get very nervous when I go to the dentist, even if it's for a } \\
\text { checkup }\end{array}$ & $3.35(1.383)$ & $3.58(1.300)$ & 0.005 \\
\hline 17. When I go to the dentist I'm not nervous, but relaxed (R) & $2.83(1.317)$ & $2.48(1.315)$ & 0.000 \\
\hline 18. I do not damage my teeth with cavities because it is painful & $1.95(1.020)$ & $2.03(1.057)$ & 0.152 \\
\hline 19. If I can avoid the dentist, I avoid & $3.44(1.234)$ & $3.39(1.284)$ & 0.562 \\
\hline 20. I try not to go to the dentist because I have a fear of needles & $4.20(1.034)$ & $4.09(1.120)$ & 0.096 \\
\hline 21. I believe that if I go to the dentist I will always have pain & $3.24(1.352)$ & $3.26(1.303)$ & 0.808 \\
\hline \multicolumn{4}{|l|}{ Dental Aesthetics dimension } \\
\hline 1. I do not worry about keeping my teeth clean since no one sees them & $4.79(0.578)$ & $4.52(0.806)$ & 0.000 \\
\hline 2. I do not brush my teeth because I do not think it works at all & $4.85(0.486)$ & $4.66(0.664)$ & 0.000 \\
\hline 3. It is not important to keep my teeth for a lifetime & $4.79(0.548)$ & $4.57(0.770)$ & 0.000 \\
\hline $\begin{array}{l}\text { 4. I do not really think much about the appearance or the look of my } \\
\text { teeth }\end{array}$ & $4.73(0.617)$ & $4.47(0.812)$ & 0.000 \\
\hline $\begin{array}{l}\text { 5. I'm more concerned about being well dressed than taking care of my } \\
\text { mouth }\end{array}$ & $4.31(0.864)$ & $4.07(0.972)$ & 0.000 \\
\hline $\begin{array}{l}\text { 6. I do not take care of my mouth even though my parents always } \\
\text { remember me to do it }\end{array}$ & $4.67(0.737)$ & $4.39(0.889)$ & 0.000 \\
\hline \multicolumn{4}{|l|}{$\begin{array}{lc}\text { Health Concerns dimension } \\
\end{array}$} \\
\hline $\begin{array}{l}\text { 8. If you had any dental problems, no matter how small, I would } \\
\text { immediately seek a dentist (R) }\end{array}$ & $1.85(0.908)$ & $2.12(0.993)$ & 0.000 \\
\hline 9. I usually follow my dentist's advice $(\mathrm{R})$ & $1.77(0.826)$ & $1.99(0.970)$ & 0.000 \\
\hline 11. I intend to maintain good oral health since it is important to me (R) & $1.43(0.744)$ & $1.71(0.863)$ & 0.000 \\
\hline 12. I intend that my friends and family to have good oral hygiene (R) & $2.33(0.993)$ & $\begin{array}{c}2.53 \\
(1.120)\end{array}$ & 0.001 \\
\hline \multicolumn{4}{|c|}{ Oral Problems Prevention dimension } \\
\hline 10. I think I need to go to the dentist at least once a year (R) & $1.65(0.951)$ & $1.81(1.014)$ & 0.005 \\
\hline $\begin{array}{l}\text { 23. Oral health should be taught from an early age so that we do not } \\
\text { have problems when we are adults (R) }\end{array}$ & $1.73(1.099)$ & $1.91(1.116)$ & 0.006 \\
\hline $\begin{array}{l}\text { 24. I believe we should go to the dentist to know how to prevent } \\
\text { cavities and gum problems (R) }\end{array}$ & $2.01(0.995)$ & $2.08(1.041)$ & 0.277 \\
\hline 25. The inflammation of the gums is of no importance to my health & $4.37(0.966)$ & $4.16(1.047)$ & 0.001 \\
\hline $\begin{array}{l}\text { 26. I think we should be interested and ask the dentist how to prevent } \\
\text { diseases of the teeth and gums (R) }\end{array}$ & $1.65(0.886)$ & $1.86(0.982)$ & 0.000 \\
\hline 27. If my gums were bleeding, I'd go to the dentist (R) & $2.04(1.081)$ & $2.16(1.118)$ & 0.079 \\
\hline \multicolumn{4}{|l|}{$\begin{array}{ll}\text { General Health dimension } \\
\end{array}$} \\
\hline 7. Teeth are important for the health of my whole body (R) & $1.62(1.007)$ & $1.81(1.128)$ & 0.002 \\
\hline 22. Having good oral health is important to make me feel good (R) & $1.88(1.032)$ & $2.01(1.031)$ & 0.033 \\
\hline 28. Having healthy teeth is very important to eat well $(\mathrm{R})$ & $1.77(0.940)$ & $1.78(0.952)$ & 0.967 \\
\hline
\end{tabular}

Source: Authors

situation with the dental fear dimension results were found in this study: boys showed less independence seeking dental treatment comparing to girls $(\mathrm{p}<0.05)$. Also both studies revealed that girls, however, were more nervous than boys at the dental office ( $<<0.01$ in both studies). There were more studies that showed significant differences between genders in dental anxiety (girls having higher levels of anxiety than boys) (Bedi et al., 1992; Peretz \&Efrat, 2000). A repeated cross-sectional study over 30 years in Sweden showed the proportions of dentally anxious during the period (1973 2003 ) were $38 \%$ in $1973,26 \%$ in $1983,18 \%$ in 1993 and $13 \%$ in 2003 . These findings showed a clearly decreasing trend over time. The strongest predictor of dental anxiety was gender, with girls 
reporting higher levels of dental anxiety (Stenebrand et al., 2015). This study showed that the dentally anxious were $28.3 \%$ of respondents in Klaipeda city. If we compare this score with those findings of the Swedish study (Stenebrand et al., 2015), we can see that a similar amount of dentally anxious adolescents in Sweden were in 1983 (26\%).

Girls more frequently than boys had an attitude that teeth should be kept clean for aesthetic purposes. There was a study of oral health-related quality of life among adolescents studying in Klaipeda, that showed girls more often than boys $(p<0.05)$ expressed dissatisfaction because of the space between the teeth, the color of their teeth, tooth shape or size or position of the dental arch (Andruskiene et al., 2014). Malocclusion, which is very related to dental aesthetics, often causes lower self-esteem in girls compared to boys. The study of the effect of malocclusion on the self-esteem of adolescents showed a highly statistically significant difference in self-esteem between genders; $31 \%$ of girls showed low levels of self-esteem versus $17.1 \%$ of boys $(\mathrm{P}<0.001)$ (Mahmoud Taibah \&Mohammed Al-Hummayani, 2017). Another study in Columbia also showed a negative correlation $(\mathrm{r}=-0.14, \mathrm{p}<0.05)$ in girls between the Dental Aesthetic Index (DAI) and self-esteem (Mafla et al., 2011).

Girls preferred to seek a dentist's help as soon as it is needed and to maintain good oral health, to ensure teeth longevity and because it's essential for human health in general. A study of adolescents in Riyadh City in 2013 showed a statistically significant difference (in favor of girls) related to the knowledge about bleeding gums, and how oral health effects general health with the $p$ value of $<0.001,<0.05$, respectively (Al Subaitac et al., 2015).

Many studies showed, that girls were more concerned with their oral and general health, including dental aesthetics. Dental anxiety was quite common in a population of adolescents in Klaipeda, girls being more dentally anxious, comparing to boys. This shows the necessity of measures to be taken to prevent dental anxiety. Previous pain experiences during dental care treatment is a strong predictor for high dental anxiety in 15-year olds (Stenebrand et al., 2015). Dentists should be aware of this factor when assessing dental anxiety in their patient populations.

\section{Conclusions}

Girls demonstrated better oral health care habits, comparing to boys. Boys had greater, as compared to girls, dental fear, restricting them from having regular appointments for check-ups at the dental office. Girls more frequently than boys had an attitude that teeth should be kept clean for aesthetic purposes and in order to ensure their longevity. Girls preferred to seek a dentist's help as soon as it is needed and to maintain good oral health, because it's essential to human health in general.

\section{References}

Andruškienè, J., Iždonaitè-Medžiūnienè, I., Grubliauskienè, J. (2014). Oral health-related quality of life among adolescents studying in schools of Klaipèda. Visuomenès sveikata. 2014/priedas Nr. 1, 70-74.

Astrom, A.N., (2004). Stability of oral health-related behaviour in a Norwegian cohort between the ages of 15 and 23 years. Community Dentistry and Oral Epidemiology 32, 354-362.

Al Subaitac, A., Alousaimi, M., Geeverghese, A., Ali, A., Metwally, A. (2015). Oral health knowledge, attitude and behavior among students of age 10-18 years old attending Jenadriyah festival 4. Riyadh; a cross-sectional study. The Saudi Journal for Dental Research. Volume 7, Issue 1, January 2016, 45-50.

Bedi, R, Sutcliffe, P, Donnan, PT, McConnachie, J. (1992). The prevalence of dental anxiety in a group of 13- and 14-year old Scottish children. Int J Paediatr Dent. 1992; 2, 17-24.

Fagerstad, A., Windahl, J., Arnrup, K. (2016). Understanding avoidance and non-attendance among adolescents in dental care - an integrative review. Community Dental Health 33, 195-207.

Health Behavior In School-aged Children (HBSC) Study: International Report from the 2013/2014 Survey.

Honkala, S., Vereecken, C., Niclasen, B., Honkala, E. (2015). Trends in toothbrushing in 20 countries/regions from 1994 to 2010. European Journal of Public Health 25, 20-23.

Inchley, J., Currie, D., Young, T., Samdal, O., Torsheim, T., Augustson, L., Mathison, F., Aleman-Diaz, A., Molcho, M., Weber, M., et al. (2016). Growing up Unequal: Gender and Socioeconomic Differences in Young People's Health and WellBeing. Health Behaviour in School-Aged Children (HBSC) Study: International Report from the 2013/2014 Survey. World Health Organization Regional Office for Europe; Copenhagen, Denmark: 2016. Health Policy for Children and Adolescents, No. 7.

Kanli, A., Kanbur, N.O., Dural, S., Derman, O. (2008). Effects of oral health behaviors and socioeconomic factors on a group of Turkish adolescents. Quintessence International 39, 26-32. 
Mafla, A.C., Luna, E.G., Sánchez, N.R., Barrera, D.A., Muñoz, G.M. (2011). Dental aesthetics and self-esteem in adolescents. Colomb. Med. vol.42 no.4 Cali Oct./Dez.

Mahmoud Taibah, S., Mohammed, Al-Hummayani, F. (2017). Effect of malocclusion on the self-esteem of adolescents. J Orthod Sci. 2017 Oct-Dec; 6(4), 123-128.

Nordström, A., Birkhed, D. (2017). Attitudes and behavioural factors relating to toothbrushing and the use of fluoride toothpaste among caries-active Swedish adolescents - a questionnaire study. Acta Odontologica Scandinavica 75, 483-487.

Peretz, B., Efrat, J. (2000). Dental anxiety among young adolescent patients in Israel. International journal of paediatric dentistry. 2000, 6.

Poulton, R., Waldie, K.E., Thomson, W.M., Locker, D. (2001). Determinants of early- vs late-onset dental fear in a longitudinal-epidemiologic study. Behaviour Research and Therapy 39, 777-785.

Silk, H., Kwok, A. (2017). Addressing Adolescent Oral Health: A Review Health Behaviour in School-aged Children (HBSC) Study: International Report from the 2013/2014 Survey, 38(2), 61-68.

Skaret, E., Raadal, M., Kvale, G., Berg, E. (2000). Factors related to missed and cancelled dental appointments among adolescents in Norway. European Journal of Oral Sciences 108, 175-183.

Stenebrand, A., Wide Boman, U., Hakeberg, M. (2013). Dental anxiety and temperament in 15-year olds. Acta Odontologica Scandinavica, ISSN 0001-6357, E-ISSN 1502-3850, 71(1), 15-21.

Stenebrand, A., Hakeberg, M., Nydell Helkimo, A., Koch, A. (2015). Dental anxiety and oral health in 15-year-olds: a repeated cross-sectional study over 30 years. Community Dental Health, ISSN 0265-539X, 32(4), 221-225. 